\title{
PEMBERDAYAAN KEMAMPUAN LANSIA DALAM DETEKSI DINI PENYAKIT DEGENERATIF
}

\author{
Widodo, Sumardino \\ Kementerian Kesehatan Politeknik Kesehatan Surakarta Jurusan Keperawatan
}

\begin{abstract}
Awareness, Early Detection Capabilities And Community Empowerment. This study aims to improve the ability of elderly people in the early detection of degenerative diseases in Posyandu Melati III Tegalrejo, Ceper, Klaten. While the specific purpose of this study was to describe the initial knowledge of early detection of degenerative diseases, describing the changes of knowledge and capacity for early detection of degenerative diseases post-counseling and training. This study used a quasi-experimental research design (quasy-experiment). The data source of this research is a group of elderly Posyandu Bed III Tegalrejo, Ceper, Klaten with the method of selecting sample is total population. The tools used in this study was a questionnaire to evaluate the cognitive, psychomotor aspects SOP to evaluate and extension materials. Results showed that changes in knowledge and capacity for early detection of the elderly against degenerative diseases in Posyandu Melati III Tegalrejo, Ceper, Klaten. This is evident from the test results of paired t-test with a significance value 0.000>0.05. The provision of health education and training early detection of degenerative diseases can increase knowledge of the initial capital to raise public awareness about the importance of early detection capabilities against degenerative diseases so that the quality and degree of health of the elderly can be optimized.
\end{abstract}

Keywords: Awareness, Early Detection Capabilities And Community Empowerment

\begin{abstract}
Abstrak: Pengetahuan, Kemampuan Deteksi Dini Dan Pemberdayaan Masyarakat. Penelitian ini bertujuan untuk meningkatkan kemampuan masyarakat lansia dalam upaya deteksi dini penyakit degeneratif di posyandu lansia Melati III Desa Tegalrejo, Ceper, Klaten. Sedangkan tujuan khusus penelitian ini adalah untuk mendeskripsikan pengetahuan awal deteksi dini penyakit degeneratif, mendeskripsikan perubahan pengetahuan dan kemampuan deteksi dini penyakit degeneratif paska penyuluhan dan pelatihan. Penelitian ini menggunakan rancangan penelitian eksperimen semu (quasy-eksperiment). Sumber data penelitian ini adalah kelompok lansia posyandu lansia Melati III Desa Tegalrejo, Ceper, Klaten dengan metode pemilihan sample adalah total populasi. Alat yang digunakan dalam penelitian ini adalah kuesioner untuk mengevaluasi aspek kognitif, SOP untuk mengevaluasi aspek psikomotor dan materi penyuluhan. Hasil penelitian menunjukkan adanya perubahan pengetahuan dan kemampuan deteksi dini para lansia terhadap penyakit degeneratif di posyandu lansia Melati III Desa Tegalrejo, Ceper, Klaten. Hal ini terlihat dari hasil uji paired t-test dengan nilai signifikansi $0.000<0.05$. Pemberian pendidikan kesehatan dan pelatihan deteksi dini penyakit degeneratif dapat meningkatkan pengetahuan yang merupakan modal awal untuk menyadarkan masyarakat akan pentingnya kemampuan mendeteksi
\end{abstract}


dini terhadap penyakit degeneratif sehingga kwalitas dan derajad kesehatan lansia dapat dioptimalkan.

Kata Kunci: Pengetahuan, Kemampuan Deteksi Dini Dan Pemberdayaan Masyarakat

\section{PENDAHULUAN}

Keberhasilan pembangunan
nasional khususnya pembangunan nasional bidang kesehatan salah satunya terlihat dari semakin meningkatnya usia harapan hidup masyarakat Indonesia. Sebagai konsekwensinya maka jumlah penduduk usia lanjut juga semakin meningkat. Data dari WHO (2008) menunjukkan adanya peningkatan jumlah penduduk lanjut usia (lansia) di mana antara tahun 2006 dan 2015 jumlah penduduk berusia 60 tahun atau lebih, akan berlipat dari 650 juta $(11 \%)$ dari poulasi global menjadi 2 miliar orang (22\%). Demikian juga data yang disampaikan oleh Pusparini (2011) yang menunjukkan adanya kecenderungan yang sama di mana pada tahun 2015 populasi lanjut usia di seluruh dunia diperkirakan menjadi 1,2 miliar dan 840 juta di antaranya berada di Negara-negara berkembang.

Sementara di Indonesia, menurut data dari Badan Pusat Statistik (2012), pada tahun 2012 diperkirakan jumlah penduduk lansia di Indonesia berjumlah 18,55 juta jiwa atau $(7,78 \%)$ dari total penduduk Indonesia, dan Jawa Tengah berkontribusi pada $10 \%$ penduduk berkelompok usia lanjut pada urutan ketiga setelah DI Yokyakarta dan Jawa Timur. Angka 7 persen mengindikasikan bahwa Indonesia sudah masuk kepada Negara berstruktur tua (aging population). Pusparini (2011) juga menyebutkan proporsi populasi lansia Indonesia pada tahun 2020 diperkirakan mencapai $11,34 \%$. Pada saat itu jumlah penduduk dengan usia lanjut diperkirakan jauh lebih banyak dibandingkan jumlah penduduk anak-anak atau di bawah 16 tahun. Peningkatan jumlah penduduk usia lanjut tersebut tidak hanya terjadi di Negara maju tetapi juga terjadi di negara-negara berkembang termasuk Indonesia.

Jika dilihat dari angka kesakitan penduduk lansia, maka pada tahun 2012 terdapat $26,93 \%$ penduduk yang sakit yang artinya bahwa dari setiap 100 orang lansia terdapat 27 orang di antaranya mengalami sakit. Meskipun ada peningkatan derajad kesehatan pada kelompok penduduk lansia namun secara umum hampir di semua propinsi derajad kesehatan penduduk lansia masih cenderung sangat rendah. Rendahnya derajad kesehatan salah satunya dipengaruhi oleh proses salami dari menua (aging process).

Proses menua merupakan proses yang dihasilkan akibat menurun atau menghilangnya kemampuan untuk mempertahankan keseimbangan dan regulasi sistim tubuh (Dillon, 2007; Vicky, 2012). Kemampuan berbagai organ dan sel untuk mempertahankan bentuk dan fungsi berangsur-angsur menghilang (Van Leeuwen, Kranpitz, Smith, 2006). Penurunan bentuk dan fungsi tubuh tersebut mempunyai potensi timbulnya masalah baru pada lansia tersebut sehingga kelompok masyarakat ini menjadi sangat rentan terhadap permasalahan kesehatan. Gangguangangguan kesehatan kecil yang pada situasi normal tidak berdampak pada masalah aktivitas sehari-hari, pada saat 
gangguan tersebut meningkat atau berlebihan dapat berakibat sangat serius pada lansia tersebut.

$$
\text { Data dari BPS (2012) }
$$

menunjukkan bahwa keluhan kesehatan lansia yang paling tinggi adalah keluhan yang merupakan efek dari penyakit kronis seperti asam urat, darah tinggi, rematik, darah rendah dan diabetes $(32,99 \%)$, disusul batuk $(17,81 \%)$ dan pilek $(11,75 \%)$. Sementara itu prevalensi obesitas yang paling tinggi menjelang lansia sampai lansia (kelompok umur 5564 tahun, 65-74 tahun dan 75 tahun atau lebih) adalah kelompok umur 55-64 tahun $(23,1 \%)$. Dilihat dari jenis penyakit Sistem Informasi Rumah Sakit (SIRS) tahun 2010, disebutkan bahwa 10 peringkat terbesar penyakit penyebab rawat jalan dari seluruh penyakit rawat jalan pada kelompok usia 45-64 tahun dan 65 tahun atau lebih yang paling tinggi adalah hipertensi esensial (primer).

Pada penelitian yang dilakukan oleh Sudiono (2008) di Jakarta Timur, ditemukan penyakit degereratif seperti Hipertensi, Diabetes dan penyakit jantung. Di antara penyakit tersebut, hipertensi menduduki peringkat pertama $(45,5 \%)$ dan diikuti DM $(3,6 \%)$. Temuan berikutnya adalah adanya permasalahan dengan perawatan kebersihan mulut (oral hygiene) sebanyak 55\%. Dengan melihat sebagian temuan-temuan tersebut maka kelompok penduduk lanjut usia perlu mendapatkan kemampuan perawatan diri seperti mengenali potensi masalah sedini mungkin, mengetahui cara mencari pertolongan saat diketahui atau dirasakan mengalami masalah kesehatan serta ada kesadaran dan peran serta masyarakat untuk memberikan penguatan terhadap upaya-upaya tersebut sehingga permasalahan yang sebenarnya dapat diantisipasi secepatnya.

Pada umumnya cukup sulit mengenali secara dini permasalahan kesehatan yang terjadi pada usia lanjut (Vicky, 2012). Kebanyakan gejala dan tanda yang muncul tidak spesifik sehingga sering kali masalah dikenali ketika sudah berlanjut. Hal ini semakin sulit karena munculnya tanda dan gejala natural dari proses menua dan kondisi kronis yang kompleks yang dapat mengaburkan tanda atau gejala yang sebenarnya menunjukkan adanya permasalahan kesehatan. Keadaan kadang menjadi tambah sulit karena sebagian masyarakat Indonesia juga belum memiliki kesadaran penuh untuk peduli terhadap upaya deteksi dini terhadap potensi masalah yang akan dihadapinya. Berbagai perubahan yang sering terjadi pada kesehatannya sering dirasakan namun kadang tidak mendapatkan tindak lanjut atau bahkan tidak dihiraukan sama sekali. Sebagian besar masyarakat akan mencari tempat pemeriksaan atau pengobatan ketika masalah kesehatan atau bahkan komplikasi dari penyakit sudah terjadi.

Namun secara umum, masyarakat juga memiliki pengalaman, pengetahuan dan interaksi dengan masyarakat yang perlu dioptimalkan berkaitan dengan postensi masalah dan pengetahuan dan cara mengatasinya. Kesadaran akan perlunya kebutuhan deteksi dini dan perawatan dini ini dapat meningkatkan efektifitas penanganan pada saat kelompok ini mengalami masa kesehatan dan kegawatan. Dengan demikian tingkat kemandirian dan kwalitas hidup usia lanjut dapat dipertahankan bahkan ditingkatkan.. 


\section{METODE PENELITIAN}

Penelitian ini termasuk penelitian eksperimen yang merancang dan memberikan perlakuan kemudian menguji efektivitas pengaruh perlakuan tersebut. Penelitian ini menggunakan rancangan penelitian eksperimen semu (quasyeksperiment) dengan skema : Rancangan One Group Pretest - Posttest Design

Ruang lingkup penelitian ini dibatasi pada area pemberdayaan masyarakat usia lanjut dalam mendeteksi dini pada penyakit degeneratif yang mencakup upaya peningkatan promosi kesehatan. Sasaran penelitian ini adalah Para Lansia yang tergabung dalam pelayanan Posyandu Lansia "Melati III" Desa Tegalrejo, Ceper, Klaten yang dilaksanakan pada bulan April-Juli 2015. Populasi Populasi dalam penelitian ini adalah masyarakat usia lanjut di Posyandu Lansia "Melati III" Desa Tegalrejo, Ceper, Klaten dengan sampelnya adalah menggunakan total sapling. Variabel pada penelitian ini terdiri dari dua variabel bebas yaitu pemberdayaan masyarakat dan variabel terikatnya adalah kemampuan deteksi dini penyakit degeneratif. Instrumen yang digunakan dalam penelitian ini adalah Quesioner yang terdiri dari 20 pernyataan dan Standar Operasional Prosedur (SOP) untuk panduan unjuk kerja deteksi dini dari masing-masing penyakit. $\mathrm{Uji}$ validitas dan reliabilitas instrumen dilakukan dengan uji coba instrumen kepada 10 lansia yang tidak diikutkan dalam penelitian dengan pertimbangan agar diperoleh distribusi nilai hasil pengukuran yang mendekati normal (Notoatmodjo, 2007). Setelah instrumen penelitian diujicobakan kemudian dilakukan analisis untuk mengetahui validitas item-item kusioner dengan menggunakan formula Korelasi Product Moment dari Pearson. Cara pengambilan data dalam penelitian ini menggunakan data primer yang diperoleh secara langsung dari responden, yaitu dari hasil pengisian kuesioner dan data sekunder yang diperoleh secara tidak langsung yaitu dari dokumentasi (medical record) yang diperoleh dari fasilitas pelayanan posyandu mengenai catatan pelayanan kesehatan masyarakat lansia.

\section{HASIL PENELITIAN}

Data demografi meliputi ditribusi frekuensi berdasarkan kelompok umur, jenis pendidikan dan jenis kelamin. Sebagian besar responden berusia di atas 56 tahun yaitu 36 orang (92\%) dan hanya 3 orang yang berusia kurang dari 56 tahun. Responden berpendidikan akhir Sekolah Dasar juga mendominasi yaitu 48,7\% ( $=19)$, diikuti pendidikan SMA $30,8 \%(n=12)$ dan SMP 20,5 \% ( $n=8)$. Dari jenis kelamin mayoritas responden adalah perempuan yaitu $89,7 \% \quad(n=35)$ dan hanya $10,3 \%(n=4)$ responden yang berjenis kelamin laki-laki.

Hasil pre-test deteksi dini penyakit degenerative didesksipsikan bahwa deviasi jawaban diperoleh responden cukup besar. Dari 20 jumlah butir pertanyaan yang diajukan, skor jawaban tertinggi 17 butir dan skor terendah adalah 5 butir jawaban benar. Berdasarkan gradasi jawaban benar dapat dijelaskan bahwa jawaban terendah yaitu kurang dari 8 butir jawaban 10 responden (25.6\%). Mayoritas responden berada pada jawaban rentang tengah dengah kisaran jawaban benar antara $8-14$ butir jawaban yaitu sejumlah 23 responden (59\%). Hanya 6 responden (15.4\%) memberikan jawaban benar yaitu antara $15-20$ jawaban benar. Deviasi jawaban dari 
responden pada saat post-test deteksi dini penyakit degenerative lebih kecil dibandingkan ketika belum mendapatkan pendidikan kesehatan. Jumlah jawaban terendah dari responden setelah mendapatkan penyuluhan adalah 13 butir dan jababan tertinggi 19 butir jawaban. Rentang jawaban responden adalah mayoritas jumlah responden dengan butir jawaban benar antara 15 - 20 pertanyaan adalah sejumlah 35 responden (89.7\%). Pada post-test sudah tidak ada responden yang menjawab pertanyaan dengan benar kurang dari 8 butir jawaban. Hanya 4 responden yang memberikan jawaban benar antara $8-14$ butir.

Uji normalitas data dilakukan dengan menggunakan Shapiro-wilk karena jumlah reponden kurang dari 50. Dari hasil uji normalitas pada saat pre-test menunjukkan bahwa sig. value $=0.181$ lebih besar dari 0.05 dan pada saat post test menunjukkan sig. value $=0.070$. lebih besar dari 0,05. Ini berarti bahwa kedua hasil berdistribusi secara normal. Berdasakan hasil tersebut maka uji beda pada penelitian ini menggunakan paired T-test. Hasil uji beda tersebut adalah ratarata tingkat pengetahuan sebelum dan setelah penyuluhan adalah meningkat terlihat dari peningkatan nilai mean sebelum pemberian pendidikan yaitu 10,4 menjadi 15,9 setelah pemberian pendidikan. Rata-rata pengetahuan responden sebelum dan setelah pemberian pendidikan kesehatan ada peningkatan dari 10.4 menjadi 15.9. Pada nilai signifikansi diperoleh nilai $0.000<0.05$ yang menunjukkan adanya perbedaan tingkat pengetahuan responden dalam deteksi dini tiga penyakit degeneratif.

\section{PEMBAHASAN}

Pesatnya pembangunan nasional khususnya pembangunan bidang kesehatan telah memberikan kontribusi positif terhadap berbagai capaian di bidang kesehatan. Umur Harapan Hidup (UHH) yang ditargetkan oleh pemerintah telah menunjukkan adanya kecenderungan ketercapaian yaitu 71,7 tahun pada tahun 2020. Tingginya jumlah penduduk lansia dapat berpotensi yang positif terhadap pembangunan jika kualitas dan produktifitas lansia dapat dikelola dan dipertahankan dengan baik. Namun jika kelompok penduduk ini tdak mendapatkan perhatian dan pengelolaan dengan baik maka dapat menimbulkan berbagai permasalahan yang komplek baik dari segi ekonomi, sosial, kesehatan dan sebagainya dan sekaligus menjadi beban bagi pemerintah. Untuk menjadikan penduduk lansia tetap produktif, sehat dan tangguh membutuhkan banyak persiapan, dukungan dan komitmen dari semua pihak. Meningkatnya jumlah penduduk lansia diprediksi menjadi bonus demografi kedua bagi Indonesia.

Perilaku masyarakat sering menjadi faktor penyebab yang utama terjadinya permasalahan kesehatan. Masyarakat khususnya usia lanjut perlu mengenal potensi masalah yang mungkin akan dialaminya. Deteksi dini tanda atau gejala penyakit merupakan salah satu langkah awal untuk mencegah terjangkitnya penyakit degeneratif. Usia lanjut memerlukan keterampilan deteksi dini seiring dengan adanya kemunduran berbagai fungsi tubuh dan kecendurungan ketergantungan terhadap orang lain. Pada usia 60 tahun ke atas seseorang mulai berhadapan pada berbagai masalah kesehatan yang kompleks. Perubahan fisiologis akibat proses menua dapat 
memberikan respon patofisiologi yang berbeda-beda akibatadanya stimulis dari luar. Proses pengaturan tubuh menjadi kurang efisien dibandingkan dengan ketika masi muda sehingga menghasilkan pola-pola penyakit yang tidak khas (Rehman \& Qazi, 2013). Keberadaan penyakit sebelumnya atau ketika masih muda dapat menambah lebih sulitnya proses identifikasi terhadap keberadaan penyakit pada saat usia lanjut.

Fase pra lansia yang juga sudah tampak partisipasinya dalam penelitian ini yaitu 53,9 \% ( $\mathrm{n}=21)$ dengan usia kurang dari 60 tahun merupakan suatu isarat positif adanya kepedulian dan kesadaran para pra lansia terhadap kondisi kesehatannya. Langkah antisipasi positif kelompok umur tersebut untuk terlibat dalam proses peningkatan pengetahuan dan pemberdayaan diri dalam rangka meningkatkan derajad kesehatan dan produktifitas pada saat memasuki masa lansia. Tenaga kesehatan khususnya yang berada di masyarakat memegang peranan yang cukup penting dalam upaya meningkatkan pemberdayaan masyarakat usia lanjut baik melalui posyandu maupun layanan kesehatan lainnya. Hal ini seiring dengan terbatasnya sumber daya manusia yang dimiliki oleh pemerintah dalam rangka mengatasi permasalahan kesehatan masyarakat yang semakin kompleks. Dengan adanya kemampuan ini maka diharapkan dengan meningkatnya usia harapan hidup maka kualitas kesehatan usia lanjut akan meningkat dan produktifitas usia lanjut juga meningkat.

Sesuai Permenkes no. 65 tahun 2013, pemberdayaan masyarakat di bidang kesehatan adalah proses pemberian informasi kepada individu, keluarga atau kelompok (klien) secara terus menerus dan berkesinambungan mengikuti perkembangan klien, serta proses membantu klien, agar klien tersebut berubah dari tidak tahu menjadi tahu atau sadar (aspek pengetahuan atau knowledge), dari tahu menjadi mau (aspek sikap atau attitude), dan dari mau menjadi mampu melaksanakan perilaku yang diperkenalkan (aspek tindakan atau practice). Dari kegiatan penyuluhan yang dilakukan pada masyarakat usila di Posyandu Melati III Desa Tegalrejo, Ceper, Klaten, terbukti dapat meningkatkan pengetahuan para responden dalam hal mengenal tanda dan gejala penyakit-penyakit degeneratif. Antusiasme para responden untuk ingin tahu cukup kuat ditandai banyaknya pertanyaan yang diajukan yang sebagian besar merupakan keluhan yang sedang dirasakan pada saat kegiatan berlangsung. Jumlah penduduk lansia perempuan cenderung mendominasi jumlah penduduk lansia secara keseluruhan. Data yang dikeluarkan oleh Pusat Data dan Informasi Kesehatan Kementerian Kesehatan RI (2013) di mana jumlah penduduk lansia perempuan pada tahun 2012 sejumlah 10.046 .073 juta jiwa atau 54\%, lebih banyak dari laki-laki yang berjumlah 8.538 .832 atau $46 \%$.

Tingkat pendidikan merupakan faktor pendukung mudahnya proses transfer informasi. Pendidikan dasar yang dimiliki responden yaitu pendidikan SMA yang merupakan jumlah terbesar kedua responden memungkinkan proses penerimaan informasi lebih mudah dibandingkan dengan responden yang memiliki pendidikan dasar yang lebih rendah. Sebelum mendapatkan penyuluhan kesehatan, rata-rata 10 dari 20 butir pertanyaan terjawab dengan benar. Hal ini juga tampak adanya peningkatan rata-rata jawaban yang benar menjadi 
15,9 dan 35 responden berhasil menjawab pertanyaan dengan benar lebih dari 15 butir pertanyaan.

Pemberian penyuluhan atau pendidikan kesehatan sangat penting bagi masyarakat khususnya kelompok yang rentan atau beresiko mengalami masalah kesehatan. Usia yang sudah lanjut juga menempatkan kelompok tersebut pada kelompok masyarakat yang rentan terhadap berbagai resiko penyakit (Culo, 2012). Hal ini tidak hanya karena ketidakcukupan pengetahuan terhadap suatu potensi masalah tetapi juga dapat diakibatkan karena kurangnya dukungan dan perhatian dari lingkungannya. Pemberian informasi tentang kesehatan dilakukan untuk membangun kesadaran para lansia untuk diajak memikirkan permasalahan yang dihadapi, membuka harapan-harapan yang realistis dengan didasarkan pada kondisi fisiologisnya (Permenkes no. 65 tahun 2013). Ketika kesadaran dan pengetahuan telah terbentuk maka penggerakan lansia untuk meningkatkan kapasitas diri dalam melakukan deteksi dini akan lebih mudah dilakukan.

Untuk meningkatkan kapasitas responden dalam melakukan deteksi dini dilanjutkan dengan melatih para responden memeriksa secara langsung tanda dan gejala dini penyakit degeneratif menggunakan SOP yang telah dirumuskan. Kegiatan dilakukan didasarkan kebutuhan masyarakat, yang diharapkan selanjutnya dapat dikelola oleh masyarakat, dari masyarakat dan untuk masyarakat sendiri. Tingginya kehadiran mengindikasikan tingginya kesadaran responden dalam melibatkan diri pada upaya peningkatan status kesehatannya.

\section{KESIMPULAN DAN SARAN}

Berdasarkan hasil penelitian dan kesimpulan pada bab $\mathrm{V}$ maka dapat ditarik beberapa kesimpulan yaitu sebagai berikut:

1. Dari aspek kognitif, rata-rata responden pada penelitian ini belum mengerti tentang konsep dasar penyakit Hipertensi, strok dan DM serta cara melakukan deteksi dini terhadap penyakit tersebut.

2. Ada peningkatan pengetahuan responden mengenai konsep dasar dan deteksi dini penyakit Hipertensi, strok dan DM setelah dilakukan pemberian pendidikan kesehatan.

3. Ada peningkatan kemampuan responden dalam melakukan deteksi dini terhadap penyakit Hipertensi, strok dan DM.

Dari kesimpulan tersebut di atas maka ada beberapa saran yang perlu mendapatkan perhatian dan tindak lanjut yaitu sebagai berkut:

1. Perlunya pengembangan dan peningkatan pemberdayaan masyarakat khususnya pada kelompok masyarakat usia lanjut pada lingkup yang lebih luas sehingga kelompok masyarakat tersebut mampu menolong dirinya sendiri dari kemungkinan menghadapi masalah kesehatan yang lebih serius dan kompleks.

2. Perlunya dukungan dan komitmen dari segenap masyarakat seperti tokoh masyarakat, kader, tenaga kesehatan dan lembaga-lembaga swadaya masyarakat lainnya untuk memberikan kontribusi dan peran yang lebih aktif baik secara formal maupun informal dalam meningkatkan kemampuan kelompok lansia dalam deteksi dini dari ketiga penyakit degeneratif yang ditemukan. 


\section{DAFTAR RUJUKAN}

Badan Pusat Statistik (2012). Statistik Penduduk Lanjut Usia. Katalog BPS 4104001, tersedia di http://www.bps.go.id/hasil_publik asi/stat_lansia_2012/index3.php? pub=StatistikPend uduk Lanjut Usia 2012 diunduh pada tanggal 8 Januari 2015

Culo, S. (2012). Risk assessment and intervention for vulnerable older adults. BCMJ, Vol. 53, No. 8, October 2011, page(s) 421-425 Tersedia di http://www.bcmj.org/articles/riskassessment-and-interventionvulnerable-older-adults. diunduh pada tanggal 8 Januari 2015.

Dillon, P.M. (2007). Nursing Health Assessment : Critical Thinking, Case Studies Approach. 2nd Ed. Philadelphia: F.A. Davis Company.

Notoatmodjo, S. 2007. Promosi Kesehatan dan Ilmu Perilaku. Jakarta : Rineka Cipta.

Permenkes RI No. 65 tahun 2013. Pedoman Pelaksanaan Dan Pembinaan Pemberdayaan Masyarakat Bidang Kesehatan. Tersedia di: http://www.hukor.depkes.go.id/up _prod_permenkes/PMK\%20No.\% 2065\% 20ttg\%20Pemberdayaan $\% 2$ 0Masyarakat\%20Bidang\%20Kese hatan.pdf diunduh pada 6 Februari 2015.

Pusparini. (2011). Pemeriksaan laboratorium berkala sebagai deteksi dini penyakit kronis pada lansia. Universa Medicina Vol.24 No.1. Tersedia di : http://www.univmed.org/wp-con
tent/uploads/2011/02/Pusparini(1). pdf diunduh pada tanggal 15 Januari 2015.

Rehman, H. \& Qazi, S. (2013). Atypical manifestations of Medical conditions in the elderly. CGS Journal Of CME, Volume 3, Issue 1, 2013gs. Tersedia di: http://www.canadiangeriatrics.ca/d efault/index.cfm/linkservid/6D28B 350-EE40-28A62454B55E47D70226/showMeta/0/ diunduh pada tanggal 15 Mei 2015.

Sudiono, J. (2008). The features of degenerative diseases and their association with the loss of teeth in the elderly of East Jakarta (Indonesia). Southeast Asian J Trop Med Public Health. 2008 Jan;39(1):184-9, tersedia di http://www.ncbi.nlm.nih.gov/pub med/1856 7460 diunduh pada tanggal 15 Januari 2015.

Van Leeuwen, A.M., Kranpitz, T.R. \& Smith, L. (2006). Davi's Comprehensive Handbook of Laboratory and Diagnostic Testwith Nursing Implication. 2nd Ed. Philadelphia: F.A. Davis Company.

Vicky. (2012). The Unique Needs of Elderly Patients in the Emergency Department (Part 2). Emergency Nursing. Tersedia di: http://allnurses. com/emergencynursing/the-unique-needs761193.html. diunduh pada tanggal 8 Januari 2015. 